\title{
Tyrosine Nitration
}

National Cancer Institute

\section{Source}

National Cancer Institute. Tyrosine Nitration. NCI Thesaurus. Code C120477.

A biochemical reaction that covalently attaches a nitro group to the carbon at position 3

of the side chain benzene ring of L-tyrosine. 